\title{
Translation, Ethics and Social Responsibility
}

\begin{abstract}
This introduction to The Translator special issue on Translation, Ethics and Social Responsibility argues the need for the interpreting and translation professions, and for Interpreting and Translation Studies, to engage with the important modern focus on social responsibility. Social responsibility is increasingly a key issue in all professions, but we contend that it has been under-explored thus far in both professional and academic contexts in relation to interpreting and translation. At a time of significant political, social and technological change, interpreters and translators face many new challenges, and considering social responsibility can provide helpful insights and strategies to cope with these. However, research on social responsibility has been dominated thus far by a focus on corporate contexts; the interpreting and translation professions are distinct from this paradigm in a number of important ways. We propose that the theme of social responsibility is ripe for exploration in relation to our discipline.
\end{abstract}

Key words. Corporate Social Responsibility, Ethics, Social responsibility, Translation and Interpreting professions, Education and training

\section{Introduction}

The third Cross-Cultural Pragmatics at a Crossroads conference at the University of East Anglia in 2013 included a strand on "Professional Mediation," in which the theme of social responsibility emerged as a strong common concern across diverse contributions on interpreting, translation and other forms of cross-cultural communication. During discussions at the conference and afterwards, we became conscious that this concept was as yet undefined in relation to translation and interpreting (used here in the broadest sense, to include all forms of translation and interpreting; hereafter, 'T\&I'). Yet communication across languages and cultures clearly involves important questions for citizens and society at large, and the various participants in translated encounters - interpreter/translator, 'client', and 'user' - are confronted with broad issues of social responsibility. These issues often arise unexpectedly and with little or no prior training, preparation or opportunity to reflect on appropriate strategies to respond.

This Special Issue aims to focus attention in Translation Studies on the linked concepts of social responsibility and ethics; to understand the concept of social responsibility as it applies to important aspects of T\&I practice; to report original research on some key areas for T\&I; and to inspire new reflection on the importance of social responsibility in Translation Studies, in the T\&I professions and in education and training.

\section{Social responsibility and the translation and interpreting professions}

There is a large body of research on the theme of social responsibility in relation to business and professional settings, such as banking, human resources, law or management. The more specific term Corporate Social Responsibility (CSR) dominates in this literature. From the 1950s, there was growing awareness that "the several hundred largest businesses were vital centers of power and decision making and that the actions of these firms touched the lives of citizens at many points" (Carroll 1999, 269). Carroll traces understanding of CSR, proliferating definitions and attention to an increasing range of themes through the decades to a widely accepted and pragmatic modern summary: "The CSR firm should strive to make a profit, obey the law, be ethical and be a good corporate citizen" (1991, 43). 
Such a focus on the corporate aspects of social responsibility is problematic in relation to the T\&I professions, however. First, the CSR literature has thus far examined other professions, usually established and regulated ones such as banking. How applicable are findings from these sectors to the T\&I professions generally, or to particular specialisations such as conference interpreting in international organisations? Second, CSR addresses the organisational level rather than the self-employed or individuals, but in T\&I contexts, this 'corporate' dimension is weak or absent. CSR definitions such as Carroll's ("make a profit, obey the law, be ethical and be a good corporate citizen") apply to T\&I professionals to an extent, but what does being a "good corporate citizen" mean for the freelance translator or public service interpreter? CSR priorities and recommendations are a poor fit, given the unusually fractured, independent and geographically dispersed nature of the industry, where, moreover, many providers are unqualified or untrained. For example, in their examination of social responsibility in Human Resources (HR) settings, Parkes and Davis highlight the need for HR professionals to have the "courage to challenge" rather than be "permanent bystanders" in relation to social responsibility, and call on "professional and academic institutions internationally" to step up to their role in supporting professionals to demonstrate such courage $(2013,2411)$. But T\&I institutions and Codes of Conduct may actively discourage professionals from "challenging" anyone, instead emphasising neutrality and confidentiality. Moreover, professional and academic institutions cannot be invoked in this way when there is no mandatory formal training or regulated professional support, as is typically the case.

The concept of social responsibility is broader than that of Corporate Social Responsibility, if frustratingly nebulous. There has been a comparative lack of attention to this broader concept in the literature, but it is arguably the more relevant one for T\&I contexts. 'Caring' professions such as medicine, social work or teaching have a stronger tradition of considering social responsibility, and may therefore be a more appropriate model for T\&I than corporate sectors. In these 'caring' professions' focus on social responsibility during training, the emphasis is on (mitigating) risks: risks to society if professionals are not conscious of their broad duties and responsibilities in their work; but also risks of consequences such as burnout, stress and vicarious traumatisation for professionals themselves; see, for instance Hepworth et al. (2010) in relation to social workers. Research suggests that, beyond the reduction of harm, it makes sense to focus on social responsibility in professional contexts because it is associated with wide-reaching positive impact: the results of a large-scale empirical study indicated that "professions should develop ethical standards to encourage social responsibility, since these actions are associated with enhanced employee ethical attitudes" (Valentine and Fleischman 2008, 657). In other words, a professional focus on social responsibility may have an impact on individuals and society far beyond the narrow professional sphere.

It is our hope that devoting this Special Issue to social responsibility will lead to greater attention to this important theme in T\&I training and practice; but it is also, we argue, an important and thus far neglected topic for Translation Studies research.

\section{Issues of social responsibility in the academic context}

The question arises as to how the concept of social responsibility intersects with other perspectives and scholarship on ethics in Translation and Interpreting Studies. In order to provide some context, it is helpful to reflect on the 2001 Special Issue of this journal edited by Anthony Pym (The Return to Ethics) and consider the nature of social change that prompted a re-examination of the relation between translation and ethics at the beginning of the new millennium. Phenomena such as the rise of the Internet and issues of (global) governance highlighted by Pym may have evolved but they remain as pressing as ever, and new ones have emerged. Recent scholarship that explores the relation between translation and development studies (e.g. Marais 2014), translation and ecology (Cronin 2016), or translation and migration (Inghilleri 2017) reflects new thinking about the role of translation in human understanding, communication and survival, entailing as Marais asserts, a thorough re-examination of current epistemological positions in Translation Studies. 
In this period of late modernity, the nature and scope of global communication needs is pressing translators and interpreters into service on an unprecedented scale and in ways that often require highly reactive, as opposed to planned, approaches to practice. This comes as a double-edged sword for the profession, simultaneously raising its profile and leading to a proliferation of agents (professional and non-professional, human and non-human) that challenges the ethical landscape. For instance, although individuals are increasingly empowered through the availability of translation technologies to handle linguistic uncertainty, this is not without risk; 'citizen translators' who use online translation tools in an attempt to resolve an urgent interlingual crisis (even in courts and hospitals) shed new light on the idea of immediate coping with disequilibrium introduced in the 2001 Special Issue by Monacelli and Punzo in relation to interpreters in military settings. In this sense, 'immediate coping' is no longer viewed solely as part of the experiential reality of the interpreter, but as part of the wider experiential reality of the limited proficiency speaker (whether a 'client' or 'user'). The sidelining of human input in institutional interactions in favour of expedient, if imperfect, technology-assisted translation solutions generates new professional and disciplinary imperatives to inform public understanding of the ethical bases of interlingual and intercultural mediation and how these can effectively be managed.

The current social, political, scientific and technological landscape also raises important questions for translator selfhood and stake in society. Participatory cultures enabled by new technologies, for example, have given a platform to the enthusiastic amateur, the socially-committed professional and the activist (trained or untrained), generating both opportunities and uncertainties that have been explored in this journal, notably in the 2012 Special Issue edited by Luis Pérez-González and Şebnem Susam-Saraeva. These technologies have also shaped the increasingly fluid professional identity that is reflected in many contemporary translator profiles, bringing into relief the competing tensions facing individuals as they forge their own vision of what constitute socially responsible working practices in the wider context of their professional and personal life trajectories. For Translation Studies, approaches informed by social responsibility make it possible to move beyond questions about what motivates translators and interpreters to supply their labour (whether waged and/or unwaged) based on individual notions of what is good for society or self interest, to questions about how translation can support better living together as an ethical goal.

References in the literature to concepts such as citizen interpreters (de Manuel Jerez 2010) and activist discourses that frame translators and interpreters in more radical and often altermondialist terms (e.g. Boéri 2008) show that T\&I Studies researchers have considered aspects of social responsibility, even if it has not been conceived in such terms. These discourses position translators and interpreters as agents who not only seek to challenge the social and political order but also to permit participation in, and not just the facilitation of, social change. This has opened up an important space for contestation and dialogue: what constitutes socially responsible action for one person may be considered irresponsible by another, meaning that 'responsibility' can never be ideologically neutral and its invocation always confers an obligation to determine whose responsibility, to whom and for what. 'Responsibility' is therefore understood here as action-oriented and dynamic, encompassing value judgments and decisions that may lead as much to resistance as to acceptance and commitment to sustain a form of social consensus.

In promoting 'responsibility' as a dynamic feature of translatorial activity, it is important to recognise the now well-documented shift in the past twenty years away from deontologically-oriented approaches to translator ethics toward differentiated approaches in which the whole communicative situation is brought to bear on decision making, particularly in relation to dialogue interpreting. The concept of an ethics of service, which was described by Pym $(2001,132)$ as often outweighing any constraints to represent a particular source text, has influenced a considerable amount of scholarship in the intervening period. At the same time, in the professional sphere key questions remain, namely the problem of normative authority and the difficulty some professionals encounter in moving beyond the idea of the translator and her/his 'text' as the central ethical question. This is not to suggest a deliberate deprivileging of the text, but by framing social responsibility as a form of distributed 
responsibility, scope is created for a broader understanding of the interpersonal influences on the text situation. This issue is perhaps most keenly felt in community and public service interpreting, and many of the contributions to this collection reflect this in the examples they consider.

\section{Overview of contributions}

Paying attention to social responsibility means that the focus shifts outwards, beyond T\&I providers themselves or Translation Studies as a discipline. This collection begins with a call by Drugan to consider such broader perspectives more consistently, in particular through a focus on T\&I 'clients'. Drugan reports on experimental training in how to work effectively with interpreters and translators, delivered to social workers and advanced social work students who were about to undertake their first work placement, and argues that social responsibility means "extending our concern" to actors who are often neglected.

McDonough Dolmaya examines translation flows and language policies in crowdsourced translation platforms and revisits the relation between contested notions of minority and majority languages. She draws attention to the vexed question of rights in the context of projects organised and carried out by volunteers, specifically in relation to Wikipedia. Applying the concept of linguistic justice to considerations about how any future translation policies might achieve a better balance between fairness and efficiency, she concludes that it is possible to achieve such a balance while still conforming to the "official multilingualism" model (Patten 2001).

Harding and Ralarala also take up the issue of minority and majority languages in the context of police officers interpreting for civilian complainants in South African police stations. Focusing on oral isiXhosa and written English, they use social narrative theory to examine complex interconnected issues of "language, translation, narrative, power, law and criminal justice", effectively demonstrating how we might consider the theme of social responsibility beyond the WEIRD (Western, Educated, Industrialised, Rich and Democratic) populations which dominate research samples in Translation Studies (Mellinger and Hanson 2017, 13-21).

Gallai explores interlingual communication in police investigative interviews from a relevance-theoretical perspective, drawing examples from a corpus of authentic interpreter-mediated interviews. He shows how pragmatic interference on the part of the interpreter can disempower the interviewee and impact on the effectiveness of the Enhanced Cognitive Interview, particularly in relation to rapport building, retrieval strategy, and evidence- and information-gathering in general terms. The findings lead to calls for greater emphasis on developing pragmatic competence in both interpreter and police training.

Hlavac develops the theme of representation and re-presentation in dialogue interpreting in a contribution that focuses on close analysis of authentic interactions involving different types of linguistic mediator: child language broker, dual-role lay interpreter, professional interpreter. The analysis is informed by Merlini and Favaron's (2005) categories of interpreter footing to show how alignment to others indexes mediators' role-relationships. This serves as a basis for evaluating the mediators' sense of responsibility to the interaction as a social situation and to the positions and intentions of other participants.

Also drawing on authentic interactions, Rock demonstrates how the "monolingual norm" is rejected by socially responsible scholars, who instead recognise the complexity of forms of communication which are now common as a result of superdiversity. Using Linguistic Ethnography to examine contemporary patterns of language use, this contribution draws on Brecher's (2010) distinction between the ethical and moral and concludes that a truly moral approach to translation and interpreting may require enriched understanding of contemporary superdiverse societies.

In the final paper of the volume Tipton draws on Nussbaum's $(1997,2007)$ capabilities approach to contractarian theory in order to evaluate the role played by professional and nonprofessional volunteer interpreters in the care trajectories and institutional itineraries of survivors of domestic abuse in 
the third sector. Reporting on a case study involving an organisation in the North West of England, it sheds light on how interpreter provision supports survivors in converting capabilities into effective social participation, and the extent to which survivors are able to influence the initial contract position in relation to language services provision.

\section{Conclusion}

Taken together, the articles in the Issue, with their diverse theoretical and methodological perspectives provide examples of how translation practice may be re-articulated as a form of social responsibility. These perspectives help to enhance our understanding of what translators and interpreters do to promote social and procedural justice in relation to vulnerable groups and relevant inter-professions. They also shed light on the wider institutional and societal imperatives that impact on translation practice and the translator's social position. By emphasising responsibility as socially distributed and dynamic, a discursive space is opened up that invites reflection on the ethical implications of translators' evolving influence on scientific and technical progress, cultural production and the social and political order.

We are grateful to the organisers of the Cross-Cultural Pragmatics at a Crossroads conference, in particular Dr Marie-Noëlle Guillot, for the original inspiration and their ongoing support as this Special Issue developed; to the editors of The Translator for their enthusiastic backing and advice; and to all the anonymous reviewers who contributed feedback and suggestions. We hope that this diverse collection of articles will encourage interpreters, translators, researchers and students to reflect on the concept of social responsibility as it applies to their own practice, research and training, so that this neglected aspect of translated encounters can be more fully understood and taken into consideration in future.

\section{JOANNA DRUGAN}

School of Politics, Philosophy, Language and Communication Studies, Arts Building, University of East Anglia, Norwich, NR4 7TJ, UK. j.drugan@uea.ac.uk

\section{REBECCA TIPTON}

University of Manchester, Oxford Road, Manchester, M13 9PL, UK. rebecca.tipton@manchester.ac.uk

\section{References}

Boéri, Julie. 2008. "A Narrative Account of the Babels vs. Naumann Controversy: Competing Perspectives on Activism in Conference Interpreting." The Translator 14 (1): 21-50.

Carroll, Archie B. 1999. "Corporate Social Responsibility: Evolution of a Definitional Construct". Business and Society 38 (3): 268-295.

Carroll, Archie B. 1991. "The Pyramid of Corporate Social Responsibility: Toward the Moral Management of Organisational Stakeholders.” Business Horizons 34 (July/August): 39-48.

Cronin, Michael. 2016. Eco-Translation: Translation and Ecology in the Age of the Anthropocene. London and New York: Routledge.

De Manuel Jerez, Jesús. 2010. "From Ethics to Politics: Towards a New Generation of Citizen Interpreters". In Compromiso Social y Traducción/Interpretación, Translation/Interpreting and Social Activism edited by Julie Boéri and Carol Maier, 134-145. ECOS, Granada: Spain.

Hepworth, Dean H., Ronald H. Rooney, Glenda Dewberry Rooney, Kim Strom-Gottfried, and Jo Ann Larsen. 2010. Direct Social Work Practice: Theory and Skills. 8th ed. Belmont, CA:

Brooks/Cole CENGAGE Learning. 
Inghilleri, Moira. 2017. Translation and Migration. London and New York: Routledge.

Marais, Kobus. 2014. Translation Theory and Development Studies: A Complexity Theory Approach. New York and Abingdon: Routledge.

Monacelli, Claudia, and Roberto Punzo. 2001. "Ethics in the Fuzzy Domain of Interpreting." In The Return to Ethics edited by Anthony Pym, Special Issue of The Translator 7 (2): 265-282.

Pérez-González, Luis, and Şebnem Susam-Saraeva, eds. 2012. Nonprofessionals Translating and Interpreting: Participatory and Engaged Perspectives, Special Issue of The Translator 18 (2): 149165.

Pym, Anthony. 2001. "The Return to Ethics in Translation Studies." In The Return to Ethics, edited by Anthony Pym, Special Issue of The Translator 7 (2): 129-138.

Valentine, Sean, and Gary Fleischman. 2008. "Professional Ethical Standards, Corporate Social Responsibility, and the Perceived Role of Ethics and Social Responsibility." Journal of Business Ethics 82 (3): 657-666. 